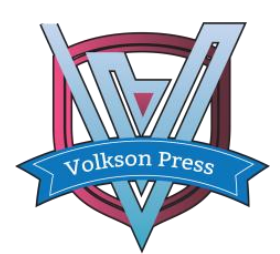

Contents List available at VOLKSON PRESS

Mechanical and Control Engineering (MCE)

DOI : http://doi.org/10.26480/wsmce.01.2017.89.91

\title{
DAMPING LAYER OPTIMIZATION DESIGN OF VISCOELASTIC CO-CURING STRUCTURE
}

\author{
Li Haiyan ${ }^{1 *}$, Xu Yang' ${ }^{2}$ Zhang Yaolei ${ }^{1}$, Li Chengxiang ${ }^{1}$, Wang Bin ${ }^{1}$ \\ ${ }^{1}$ China Academy of Launch Vehicle Technology, Fengtai, Beijing, China \\ ${ }^{2}$ Beijing Institute of Astronautical Systems Engineering, Fengtai, Beijing, China \\ *Corresponding Author Email: hain.lee@163.com
}

This is an open access article distributed under the Creative Commons Attribution License, which permits unrestricted use, distribution, and reproduction in any medium, provided the original work is properly cited

\section{ARTICLE DETAILS}

\section{Article History:}

Received 02 october 2017

Accepted 06 october 2017

Available online 11 november 2017

Keywords

Damping, Co-curing, Optimization,

Vibration

\section{ABSTRACT}

In order to improve the dynamic environment of new weapons, viscoelastic co-curing composite is widely used. The damping layer optimization of co-curing structure is the key problem to structure design. First, by comparing three different modeling methods, finite element model was established by the three-plate modeling method. Then, using topology optimization combined with size optimization strategy, co-curing damping layer parameters optimization has been accomplished. Taking damping material unit density and composite layer thickness as design variables, the objective function is to make the structural dynamic response peak minimum, and damping material volume fraction and range of layer thickness are considered as constraint conditions. Finally, through the optimization analysis vibration reduction has been realized.

\section{Introduction}

In the future, weapons will develop to high speed and high maneuverability, and the dynamic mechanical environment of vibration, impact and noise will be worse, which will affect the accuracy and reliability of inertial navigation platform and other equipment. Viscoelastic damping vibration reduction technology is widely used in dynamics control, vibration and noise reduction and other occasions for aerospace structures. The traditional way of damping mainly includes free damping layer and constrained layer damping treatment [1-3]. Both of them need to attach one or more layers of damping material, which will add more space and quality to the original structure, and that cannot meet the design requirement of light and integration. In recent years, viscoelastic composite technology has gradually developed. This material has advantages of specific strength and specific stiffness and damping, and it will be an important application direction in the future for structure design and vibration reduction of weapons and other advanced equipment.

The embedding of damping layer makes the physical properties of composite material more discontinuous along the thickness direction, which brings new technical difficulties to optimization design of co-curing composite structure. In this paper, the finite element modeling method of viscoelastic co-curing structure and damping layer optimization strategy were explored, which could lay a technical foundation for the design of vibration and noise reduction of weapon equipment in the future.

\section{VISCOELASTIC CO-CURING COMPOSITE TECHNOLOGY}

Viscoelastic co-curing composites developed in recent years is a new damping treatment method. In the process of forming composite material, viscoelastic damping material is directly laid together with fiber layers, and embedded into composites as prepreg. Then the composite is integrally formed [4].

Analyzing on the composition and structure of viscoelastic co-curing composite material, one phase in the inner layer is substantially continuous, known as matrix phase (such as resin); the other phase is dispersed and is surrounded by the matrix phase, known as reinforced phase (such as fiber); and the third phase is isotropic viscoelastic damping material. The heterogeneous solid is formed of composite materials with different properties. Resin, fiber and damping coordinates in performance, and that can greatly improve the damping properties of composite structures, which single material mechanical properties is difficult to match.

Viscoelastic damping material is directly embedded into the interior of cocuring structure. Compared with free damping and constrained damping, it is not easy to fall off and has advantages of aging resistance, fatigue resistance, impact resistance, excellent vibration and noise reduction, etc. Therefore, it can be used in weapons such as main structures (like frame structure) or secondary structures (like bracket) to realize lightweight design and vibration control.

\section{FINITE ELEMENT MODELING OF VISCOELASTIC CO-CURING} STRUCTURE

Taking the simple square plate with viscoelastic co-curing structure as an example, the finite element model was established by using the solid modeling method, the three-layer plate modeling method and the classical laminated plate modeling method respectively (Figure 1). Through modal analysis of the three models, frequency and vibration mode results were compared to find a suitable modeling method for co-curing structure optimization. The modal analysis results are given in figure 2 .

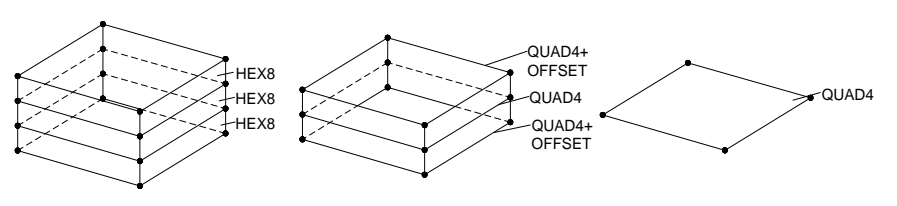

Figure 1: Three finite element modeling methods
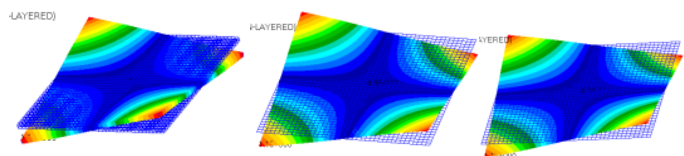
a) $53.04 \mathrm{~Hz}$
b) $54.44 \mathrm{~Hz}$
c) $53.46 \mathrm{~Hz}$

Figure 2: Comparison of modal analysis results 
According to the above analysis, the following conclusions were obtained: 1) Solid model has large scale and low efficiency, and it is not suitable for topology optimization design and analysis of complex structures;

2) Compared with the modal analysis results of the solid model, the error results of the three-layer plate model and the classical laminated plate model are relatively small, and the two modeling methods can well simulate the co-curing damping structure:

3) For the damping layer topology optimization problem, the three-layer plate model is more suitable because it needs to cut the embedded damping layer. To sum up, this paper chose the three-layer plate modeling method.

\section{DAMPING LAYER OPTIMIZATION DESIGN STRATEGY}

The damping layer optimization of viscoelastic co-curing structure has the characteristic of many design variables, large scale calculation, and etc. The design of damping layer was completed using topology optimization combined with size optimization strategy. The most commonly used sequential quadratic programming method (SQP) is used for size optimization, meanwhile, method of moving asymptotes (MMA) belongs to sequential convex programming method (SCP) is used to complete the damping layer topology optimization, which has good applicability to complicated topology $[5,6]$.

Using moving asymptotes, MMA method transforms the implicit optimization problem into a series of explicit approximate sub-problems. In each iteration, gradient algorithm is used for solving convex approximation sub-problems to obtain new design variables.

For general structural topology optimization problems, the optimization model is shown as follows,

$$
\begin{array}{ll}
\text { find } & x=\left\{x_{1}, x_{2}, \cdots, x_{n}\right\}^{T} \\
\min & f_{0}(x) \\
\text { s.t. } & f(x) \leq 0, \quad i=1,2, \cdots, m \\
& x_{j}^{\min } \leq x_{j} \leq x_{j}^{\max }, \quad j=1,2, \cdots, n
\end{array}
$$

Using MMA method to solve the problem in the formula (1), the artificial variables are introduced into the optimization model to improve each subproblem. MMA expansion is used to approximate the optimal formulation, and to establish a series of convex linear separable sub optimization problems. The mathematical models of sub optimization problems are expressed as follows,

$$
\begin{array}{llr}
\min & \tilde{f}_{0}(x)+a_{0} z+\sum_{i=1}^{m}\left(c_{i} y_{i}+\frac{1}{2} d_{i} y_{i}^{2}\right) \\
\text { s.t. } & \tilde{f}_{i}(x)-a_{i} z-y_{i} \leq 0, & i=1,2, \cdots, m \\
& \alpha_{j}^{\min } \leq x_{j} \leq \beta_{j}^{\max }, & j=1,2, \cdots, n \\
& z \geq 0, y_{i} \geq 0 & i=1,2, \cdots, m
\end{array}
$$

$Z, a_{i}, c_{i}$ and $d_{i} \geq 0$ are given constants, and $c_{i}+d_{i}>0 . y_{i}$ is constructed as a fault design variable, then $\tilde{f}_{i}$ is the approximation form of the objective function and the constraint functions in the original mathematical model, which can be expressed as

$$
\tilde{f}_{i}(x)=f_{i}^{(k)}\left(x^{(k)}\right)+\sum_{j=1}^{n} p_{i j}^{(k)}\left(\frac{1}{U_{j}^{(k)}-x_{j}}-\frac{1}{U_{j}^{(k)}-x_{j}^{(k)}}\right)+\sum_{j=1}^{n} q_{i j}^{(k)}\left(\frac{1}{x_{j}-L_{j}^{(k)}}-\frac{1}{x_{j}^{(k)}-L_{j}^{(k)}}\right)(3)
$$

In the formula, $U_{j}^{(k)}$ and $L_{j}^{(k)}$ are used to adjust the convexity of the approximate function, and the iterative scheme in the MMA method is expressed as follows:

When $k=1,2$,

$$
\begin{aligned}
& L_{j}^{(k)}=x_{j}^{(k)}-0.5\left(x_{j}^{\max }-x_{j}^{\min }\right) \\
& U_{j}^{(k)}=x_{j}^{(k)}+0.5\left(x_{j}^{\max }-x_{j}^{\min }\right)
\end{aligned}
$$

When $k>=3$,

$$
\begin{aligned}
& L_{j}^{(k)}=x_{j}^{(k)}-r_{j}^{(k)}\left(x_{j}^{(k-1)}-L_{j}^{k-1}\right) \\
& U_{j}^{(k)}=x_{j}^{(k)}+r_{j}^{(k)}\left(U_{j}^{k-1}-x_{j}^{(k-1)}\right)
\end{aligned}
$$

In the formula

$$
r_{j}^{(k)}= \begin{cases}0.7 & \left(x_{j}^{(k)}-x_{j}^{(k-1)}\right)\left(x_{j}^{(k-1)}-x_{j}^{(k-2)}\right)<0 \\ 1.2 & \left(x_{j}^{(k)}-x_{j}^{(k-1)}\right)\left(x_{j}^{(k-1)}-x_{j}^{(k-2)}\right)>0 \\ 1 & \left(x_{j}^{(k)}-x_{j}^{(k-1)}\right)\left(x_{j}^{(k-1)}-x_{j}^{(k-2)}\right)=0\end{cases}
$$

In the formula (2), $\alpha_{j}^{\min }$ 、 $\beta_{j}^{\max }$ are the moving limit parameters, and $U_{j}^{(k)}$ and $L_{j}^{(k)}$ should satisfy the following inequality,

$L_{j}^{(k)}<\alpha_{j}^{\min }<x_{j}^{(k)}<\beta_{j}^{\max }<U_{j}^{(k)}$

$p_{i j}^{(k)}$ and $q_{i j}^{(k)}$ are the first order expansion of the objective function and the constraint function for design variables at the design point $x_{j}^{(k)}$,

$$
\begin{aligned}
& p_{i j}^{(k)}=\left(U_{j}^{(k)}-x_{j}\right)^{2} \max \left(0, \frac{\partial f_{i}}{\partial x_{j}}\left(x^{(k)}\right)\right) \\
& q_{i j}^{(k)}=\left(x_{j}-L_{j}^{(k)}\right)^{2} \max \left(0, \frac{\partial f_{i}}{\partial x_{j}}\left(x^{(k)}\right)\right)
\end{aligned}
$$

There is only one nonzero for a design variable $p_{i j}^{(k)}$ or $q_{i j}^{(k)}$ at the same time. This means that, for each design variable, there is only one asymptotic line at the same time for approximation. Therefore, whether the design function is monotonic or non-monotonic, the MMA method adopts the monotone approximation process.

Starting from the design point $x^{(k)}$, the optimization problem is solved by the dual method. Based on conjugate gradient algorithm, a series of equations are solved to obtain new design variables $x^{(k+1)}=x^{*}$. Then the next iteration starts, iterates until the original problem converges to the optimal solution.

\section{DAMPING LAYER OPTIMIZATION DESIGN STRATEGY}

In the development of a new weapon, a precision equipment is extremely sensitive to vibratioin environment. In order to meet the design requirements of lightweight and integration, the equipment bracket is made of viscoelastic co-curing structure. In this paper, taking the bracket as research objective, damping layer optimization design has been carried out.

\subsection{Optimization design model}

\subsubsection{Topology optimization}

The objective function of topology optimization is to make the maximum of the structural dynamic response minimum. Design variable is the unit density of each element of damping material, and the volume fraction of damping material is set as the constraint condition.

Optimization model is as bellowing:

find: $\rho_{e} \quad e=1, \ldots, N$
$\min : \max ($ frfdis $)$
s.t. $\sum_{e=1}^{N} \rho_{e} v_{e}-\bar{v} \leq 0$

\subsubsection{Size optimization}

The objective function of topology optimization is to make the maximum of the structural dynamic response minimum. The thicknesses of each layers are taken as design variables, and the thickness of each layers should be constrained between requirement range.

Optimization model is as bellowing:

find: $h_{i} \quad i=1, \ldots, N$

$\min : \max ($ frfdis $)$ 
s.t. $\sum_{i=1}^{N} h_{i}=H$

$$
a \leq h_{i} \leq b
$$

\subsection{Optimization Results}

\subsubsection{Topology optimization}

When the volume fraction is $0.4,0.6$ and 0.8 , the topology optimization results of damping layer are shown in Figure 3, and the final damping layout of the bracket is determined as shown in figure 4 . a) 0.4

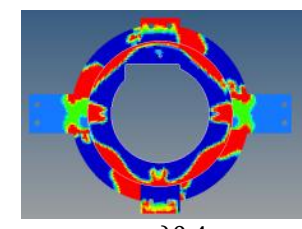

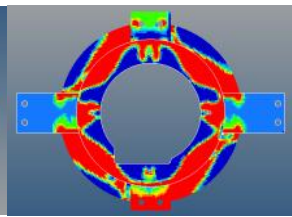

b) 0.6

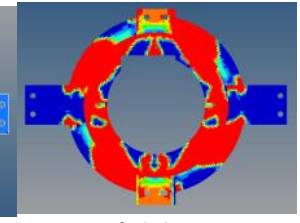

c) 0.8
Figure 3: Topology optimization results

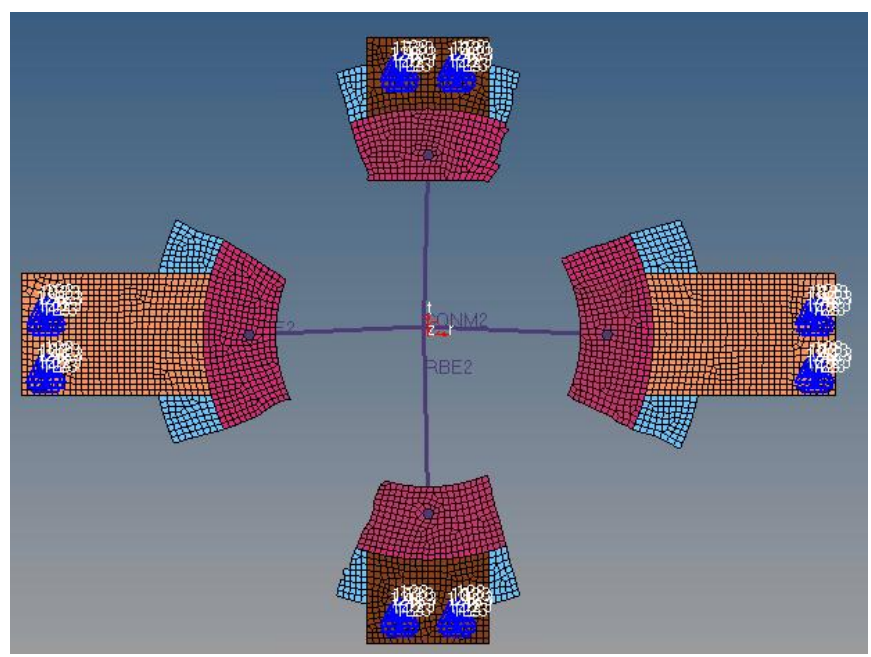

Figure 4: Damping layout of bracket

\subsubsection{Size optimization}

The convergence process of the objective function is shown in Figure 5, and Figure 6 shows the optimization results of design variables. After optimization, the results of objective function and constraint functions are shown in figure 7.

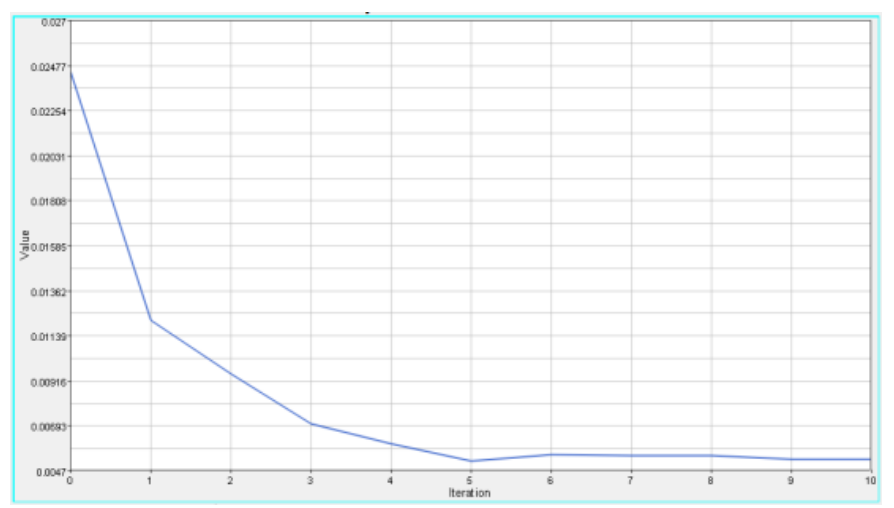

Figure 5: Convergence process of objective function

\begin{tabular}{|c|c|c|c|c|}
\hline $\begin{array}{c}\text { Design } \\
\text { Variable } \\
\text { ID }\end{array}$ & $\begin{array}{c}\text { Design } \\
\text { Variable } \\
\text { Label }\end{array}$ & $\begin{array}{l}\text { Lower } \\
\text { Bound }\end{array}$ & $\begin{array}{c}\text { Design } \\
\text { Variable }\end{array}$ & $\begin{array}{l}\text { Upper } \\
\text { Bound }\end{array}$ \\
\hline 1 & shell1 & $1.000 \mathrm{E}-02$ & $3.197 \mathrm{E}+00$ & $6.300 \mathrm{E}+00$ \\
\hline 2 & shel12 & $1.000 \mathrm{E}-02$ & $3.203 E+00$ & $6.300 \mathrm{E}+00$ \\
\hline 3 & shell3 & $1.000 \mathrm{E}-02$ & $3.185 \mathrm{E}+00$ & $6.300 \mathrm{E}+00$ \\
\hline 4 & shell4 & $1.000 \mathrm{E}-02$ & $3.186 \mathrm{E}+00$ & $6.300 \mathrm{E}+00$ \\
\hline 5 & shells & $1.000 \mathrm{E}-02$ & $1.407 \mathrm{E}+00$ & $3.300 \mathrm{E}+00$ \\
\hline 6 & shell 6 & $1.000 \mathrm{E}-02$ & $1.953 \mathrm{E}+00$ & $3.300 \mathrm{E}+00$ \\
\hline 7 & shell7 & $1.000 \mathrm{E}-02$ & $2.898 \mathrm{E}+00$ & $3.300 \mathrm{E}+00$ \\
\hline 8 & shells & $1.000 \mathrm{E}-02$ & $4.489 \mathrm{E}-01$ & $3.300 \mathrm{E}+00$ \\
\hline 9 & shellg & $1.000 \mathrm{E}-02$ & $8.243 \mathrm{E}-01$ & $3.300 \mathrm{E}+00$ \\
\hline 10 & shell10 & $1.000 \mathrm{E}-02$ & $2.568 \mathrm{E}+00$ & $3.300 \mathrm{E}+00$ \\
\hline 11 & shell11 & $1.000 \mathrm{E}-02$ & $3.059 \mathrm{E}+00$ & $6.000 \mathrm{E}+00$ \\
\hline 12 & shell12 & $1.000 \mathrm{E}-02$ & $2.942 \mathrm{E}+00$ & $6.000 \mathrm{E}+00$ \\
\hline 13 & shell13 & $1.000 \mathrm{E}-02$ & $1.235 \mathrm{E}+00$ & $6.300 \mathrm{E}+00$ \\
\hline 14 & shell14 & $1.000 \mathrm{E}-02$ & $8.710 \mathrm{E}-01$ & $6.300 \mathrm{E}+00$ \\
\hline 15 & shell15 & $1.000 \mathrm{E}-02$ & $8.759 \mathrm{E}-01$ & $3.300 \mathrm{E}+00$ \\
\hline 16 & shell16 & $1.000 \mathrm{E}-02$ & $8.461 \mathrm{E}-01$ & $3.300 \mathrm{E}+00$ \\
\hline 17 & shell17 & $1.000 \mathrm{E}-02$ & $8.768 \mathrm{E}-01$ & $3.300 \mathrm{E}+00$ \\
\hline 18 & shell18 & $1.000 \mathrm{E}-02$ & $3.480 \mathrm{E}-01$ & $6.000 \mathrm{E}+00$ \\
\hline
\end{tabular}

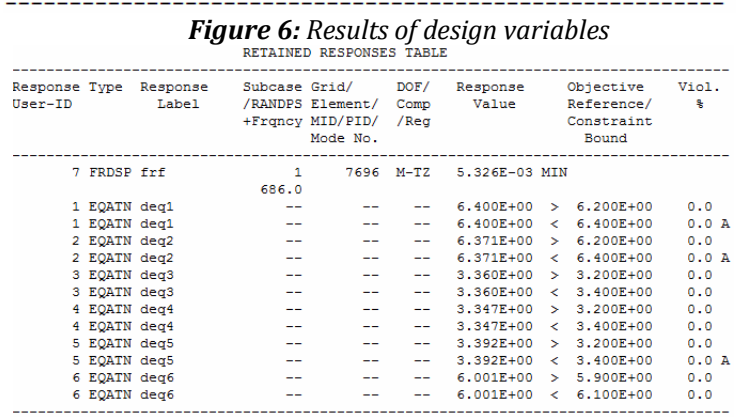

Figure 7: Results of objective function and constraint functions

It can be seen that the peak value of the structural vibration response is reduced from $2.44964 \mathrm{E}-02$ to $5.32610 \mathrm{E}-03$ after the optimization, and the damping target of the co-curing damping structure is realized.

\section{CONCLUSION}

In this paper, the finite element model of the co-curing structure was established by the three-layer plate modeling method, and damping layer optimization was completed using topology optimization combined with size optimization strategy. The research lays the foundation for engineering application of viscoelastic co-curing structure, and has a wide application prospect in aerospace and other high-tech fields.

\section{REFERENCES}

[1] Wang, C., Xu, CH. 2002. Study on vibration suppress of a cabin structure based on dynamic testing. Journal of Mechanical Strength, 24 (1), 49-51.

[2] Shen, CH., Liang, L. 2006. Vibration suppression of a payload racket in a satellite. Journal of Astronautics, 27 (3), 503-506.

[3] Shaohui, Z., Hongyou, C., Haiquan, M., Zhiying, Q. 2011. Progress and perspect on viscoelastic damping technology for spacecraft application. Spacecraft Engineering, 20 (1), 120-128.

[4] Qi-yong, Y., Yu-pu, M., Wan-tao, G., Yi-bo, W. 2007. Structural damping composite and its research progress. Materials Engineering, 2 (1) 253-258.

[5] Svanberg, K. 1987. The method of moving asymptotes- a new method for structural optimization. International Journal of Numerical Methods in Engineering, 12 (1), 359-373.

[6] Svanberg, K. 2002. A class of globally convergent optimization methods based on conservative convex separable approximations. SLAM Journal of Optimization, 12 (2), 555-573. 